\title{
Research on the establishment and method of comprehensive benefit evaluation system for smart energy systems
}

\author{
Nan $\mathrm{Xu}^{1, *}$, Zihao Zhao ${ }^{1}$,Bo Zhou ${ }^{1}$, Ningning $\mathrm{Shi}^{2}$, Yongli Wang ${ }^{3}$, Huanran Dong ${ }^{3}$ \\ ${ }^{1}$ State Grid Hebei Electric Power Co., LTD, Hebei, 050000, China \\ ${ }^{2}$ Institute of Electric Power Economy and Technology of State Grid Baoding Power Supply Company, Baoding, 071000, China \\ ${ }^{3}$ North China Electric Power University, Beijing, 102206, China
}

\begin{abstract}
The smart energy system is the new direction of the current energy development. It plays a vital role in the low-carbon development of my country's energy industry and in promoting the transformation and upgrading of the energy sector. For the construction and long-term development of smart energy systems, this paper constructs a comprehensive benefit evaluation index system for smart energy systems that can cover all aspects based on the economic, environmental protection, and reliability of energy regulation and other target benefits, and proposes a system based on AHP -Improved evaluation method of entropy weight method, aiming at the hierarchical structure of smart energy evaluation system, adopts analytic hierarchy process and improved entropy weight method to combine subjective weight and objective weight, and scientifically, reasonably and objectively the construction level of smart energy system evaluation of.
\end{abstract}

\section{INTRODUCTION}

Energy is an important material basis for the development of modern society and is closely related to national economic and social development. With the progress of world science and technology, population increase and economic development, the demand for energy, especially emerging energy, is gradually increasing. Energy saving and consumption reduction have important practical significance for solving the energy crisis in my country at this stage. With the continuous advancement of urbanization, the contradiction between urban development and the environment and resources has become increasingly prominent. With the increasing maturity and application of technologies such as artificial intelligence, cyberphysical systems, big data, and cloud computing, their integration with the energy industry will surely promote the technological upgrading of the energy industry, and smart energy systems will become the focus of future development. In order to ensure the scientific rationality of the smart energy system, analyze the different types of multi-energy supply and demand characteristics in the smart energy system, and propose a comprehensive benefit index system for the smart energy system based on the target benefits of energy regulation, such as economy, environmental protection and reliability. It is necessary to make a comprehensive assessment of the level of construction of smart energy systems.

The foundation of the smart energy system is the smart grid. The comprehensive evaluation methods of the smart grid mainly include methods based on fuzzy mathematics, methods combining fuzzy mathematics and probability theory, and methods combining analytic hierarchy process and entropy method. Aiming at the hierarchical structure of the smart energy comprehensive benefit evaluation index system considering different supply and demand characteristics, this paper uses the analytic hierarchy process (AHP)[1] to determine the subjective weight, and at the same time uses the improved entropy weight method[2] to determine the objective weight. Combining the subjectivity of expert experience and the objectivity of real data, the approaching ideal point ranking method (TOPSIS)[3] is used to comprehensively evaluate the smart energy system.

\section{Established comprehensive benefit index system for smart energy system}

Fully consider the supply and demand characteristics of smart energy systems, integrate indicators that reflect economic benefits, social benefits, and environmental benefits into energy efficiency, energy equipment, end users, etc., to build a multi-level and dimensional comprehensive benefit evaluation index system for smart energy systems, to lay the foundation for the establishment of a comprehensive benefit evaluation model for smart energy systems[4].

* Corresponding author's e-mail: szsssxxysh@163.com 


\subsection{Energy efficiency link}

(1) Energy conversion efficiency. Energy conversion efficiency (Energy Efficiency Ratio, EER) is an important indicator that reflects the energy utilization effect in the process of energy processing and conversion. It is based on the concept of energy quality coefficient and energy grade. Under the premise of meeting the same power, heat, and gas energy supply in the region, the larger the EER value, the lower the energy will be consumed of the integrated energy utilization in the smart energy system, which indirectly reflects the energy conversion efficiency of the entire smart energy system.

(2) Pollutant discharge level. Smart energy systems can be divided into combustion type and new energy type according to the sources of cold energy, heat energy and electric energy. Due to the limitations of production technology and natural conditions, smart energy equipment devices are mostly based on traditional hybrid systems such as CHP and CCHP. To this end, $\mathrm{CO} 2$ : reduction ratio ( $\mathrm{CO} 2$ Reduction Ratio, $\mathrm{CRR}$ ), $\mathrm{SO} 2$ reduction ratio (SO2 Reduction Ratio, SRR) and NOx; reduction ratio (NOx, Reduction Ratio. NRR) are used as indicators to measure the energy saving of smart energy systems. Evaluation index of environmental protection level.

(3) The level of energy economy. The input cost and energy revenue of the energy system determine its economic level. Energy Economy Level (EEL) refers to the ratio of the total economic benefits of various types of energy to the total energy input cost over a period of time. Compared with traditional energy systems, the comprehensive utilization of smart energy has brought considerable economic benefits while reducing costs.

\subsection{Energy equipment link}

(1) Utilization rate of energy equipment. Energy Equipment Utilization (EEU) refers to the ratio of the actual working time of the equipment to the planned working time in a period of time. This indicator reflects the working status and production efficiency of the equipment in the smart energy system. Its value is directly related to investment benefits.

(2) Failure rate of energy equipment. As the smart energy system involves multiple devices in multiple energy links, in terms of data acquisition and calculation, using Energy Equipment Failure Rate (EEFR) per unit of work time can simplify the evaluation process and meet the evaluation accuracy at the same time.

(3) The load rate level of the pipe network. The energy network load rate level (Energy Network Load Rate Level, ENLRL) refers to the ratio of the average load capacity to the rated load capacity, which not only reflects the ability of the smart energy system to withstand heavy load operation, but also reflects whether the energy equipment in the smart city is maximized use. In addition. Due to technical limitations and energy characteristics, there will be a certain degree of loss in the energy transmission link.

\subsection{End user link}

(1) User-side energy quality. End User Energy Quality (EUEQ) mainly includes energy quality such as electricity, heat and gas. The energy quality at the user end directly determines whether the energy can be consumed by the user and the user's energy experience.

(2) End user satisfaction. End User Satisfaction (EUS) refers to the direct experience of users participating in energy interaction in the process of energy consumption, and is an important evaluation indicator. The evaluation index can be used to collect information by issuing offline questionnaires or online feedback within a fixed period, and collect statistics on the end users' satisfaction with energy consumption during this period and reasonable suggestions.

(3) The popularity of smart meters. Smart meters (heat meters, electricity meters, water meters, gas meters, etc.) are smart terminals for end-user energy consumption billing. It has intelligent functions such as user information data collection, multi-rate two-way metering and user terminal control, which can optimize the energy use path and experience of end users, and better adapt to the comprehensive utilization and development of smart energy.

In summary, the comprehensive benefit index system of the smart energy system is shown in Table 1.

Table 1 Comprehensive benefit index system of smart energy system

\begin{tabular}{|c|c|c|}
\hline $\begin{array}{l}\text { First level } \\
\text { indicators }\end{array}$ & $\begin{array}{l}\text { Secondary } \\
\text { indicators }\end{array}$ & Indicator type \\
\hline \multirow{7}{*}{ Energy efficiency } & Energy & Economic / \\
\hline & conversion & Environmental \\
\hline & efficiency & benefits \\
\hline & Pollutant emission & Environmental \\
\hline & level & benefits \\
\hline & $\begin{array}{c}\text { Energy economy } \\
\text { level }\end{array}$ & Economic benefit \\
\hline & $\begin{array}{c}\text { Energy equipment } \\
\text { utilization }\end{array}$ & Economic benefit \\
\hline \multirow{3}{*}{$\begin{array}{l}\text { Energy } \\
\text { equipment }\end{array}$} & $\begin{array}{l}\text { Energy equipment } \\
\text { failure rate }\end{array}$ & Economic benefit \\
\hline & $\begin{array}{l}\text { Pipe network load } \\
\text { rate level }\end{array}$ & Economic benefit \\
\hline & $\begin{array}{c}\text { End-user energy } \\
\text { quality }\end{array}$ & Social benefit \\
\hline \multirow{2}{*}{ End user } & $\begin{array}{c}\text { End user } \\
\text { satisfaction }\end{array}$ & Social benefit \\
\hline & $\begin{array}{l}\text { Popularity of } \\
\text { smart meters }\end{array}$ & Social benefit \\
\hline
\end{tabular}

\section{Evaluation method of smart energy system based on AHP-improved entropy weight method}

\subsection{Calculation of index weight coefficient}

Index weight coefficient calculation. In order to make the weights have both the subjectivity of expert experience and the objectivity of real data, the weights of the first-level indicators of the smart energy system are determined by the analytic hierarchy process, and then the improved entropy weight method is used to calculate 
the next level of each index The objective weight of the secondary indicators is finally used to determine the combined weight of each secondary indicator in a hierarchical recursive manner[5,6]. ${ }^{w_{i}}$ represents the combined weight, ${ }^{w_{k}}$ represents the weight of the k-th primary index to which the i-th secondary index belongs, and $w_{i}^{\prime}$ represents the entropy weight of the i-th secondary index.

$$
w_{i}=w_{k} \times w_{i}^{\prime}
$$

\subsection{Subjective weight calculation}

The subjective weights are calculated using the analytic hierarchy process. The hierarchical classification method is a flexible and practical multi-dimensional decisionmaking method. Its basic principles and main steps are as follows:

(1) Based on the in-depth analysis of the system, a hierarchical structure model is constructed based on the index system.

(2) For indicators of the same level that belong to the same superior level, the judgment matrix is established by pairwise comparison on a scale of 1-9, and the degree of comparison is determined by Table 2 . According to the experience of experts in this field, the judgment matrix $\mathrm{A}$ is obtained.

Table 2 Definition of pairwise comparison

\begin{tabular}{cc}
\hline Scaling & $\begin{array}{c}i \text { and } j \text { are equally } \\
\text { important } \\
i \text { is slightly more } \\
\text { important than } j \\
i \text { is more important than } \\
5\end{array}$ \\
$\begin{array}{c}i \text { is more important than } \\
j\end{array}$ \\
$\begin{array}{c}i \text { is absolutely more } \\
\text { important than } j \\
\text { Median }\end{array}$ \\
reciprocal
\end{tabular}

(3)Since experts will have deviations when comparing pairwise, in order to ensure the credibility of the results, the consistency of the judgment matrix must be checked. If the consistency check fails, the judgment matrix needs to be reconstructed. The consistency check steps are as follows:

(1) Calculate the consistency check index $C I, \lambda_{\max }$ represents the maximum eigenvalue, $n_{\text {represents the }}$ order of the matrix;

$$
C I=\frac{\lambda_{\max }-n}{n-1}
$$

(2) Query the corresponding average random consistency index $R I$ according to $n$, Table 3 shows the $R I$ values of the 1-9 order matrix;

Table 3 Average random consistency index

\begin{tabular}{lc}
\hline$N$ & $R I$ \\
\hline 1 & 0 \\
2 & 0 \\
3 & 0.52 \\
4 & 0.89 \\
5 & 1.12 \\
6 & 1.24 \\
7 & 1.36 \\
8 & 1.41 \\
9 & 1.45
\end{tabular}

(3) Calculate the agreement ratio $C R$,if $C R<0.1$, judgment matrix is consistent, if $C R>0.1$, judgment matrix needs to be rebuilt;

$$
C R=\frac{C I}{R I}
$$

(4) When the consistency requirements are met, the maximum characteristic value $\lambda_{\max }$ corresponding feature vector is the weight ratio vector, and the weight of each indicator is obtained after normalization. The calculation steps of the weight vector are as follows:

(1) Sum the columns of the matrix to get the vector $B=\left[\begin{array}{lll}b_{1} & \cdots & b_{n}\end{array}\right]$;

(2) Normalized matrix $C, c_{i j}=\frac{a_{i j}}{b_{j}}$;

(3) Calculate the weight vector $w=\left[\begin{array}{lll}w_{1} & \cdots & w_{n}\end{array}\right]$, $w_{i}=\frac{\sum_{j=1}^{n} c_{i j}}{\sum_{i=1}^{n} \sum_{j=1}^{n} c_{i j}} ;$

\subsection{Objective weight calculation}

The objective weight is calculated by the improved entropy weight method. The entropy weight method determines the weight based on the amount of information provided by the data of each indicator. The greater the degree of change of the indicator, the smaller the information entropy, and the greater the amount of information provided by the indicator. The higher the degree, the greater the weight assigned. The entropy method determines the weight completely according to 
the degree of dispersion of the data, and the objectivity is guaranteed.

The calculation steps of the entropy method are as follows:

(1)Data is normalized, assuming $m$ indicators are given, where $X_{i}=\left\{X_{1}, \cdots, X_{n}\right\}$. Assuming that the value of the standardized data of each indicator is $Y_{1}, \cdots, Y$, after normalization $y_{i j}=\frac{x_{i j}-x_{\min }}{x_{\max }-x_{\min }}$;

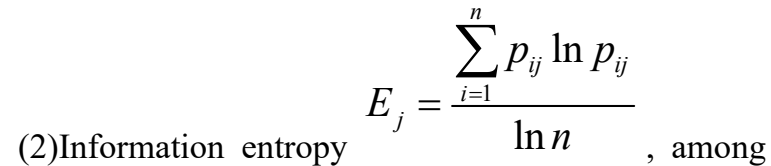
$p_{i j}=\frac{y_{i j}}{\sum_{i=1}^{n} y_{i j}}$;

(3)Calculate the weight according to the entropy value of each indicator, $w_{i}=\frac{1-E_{i}}{\sum_{i=1}^{k} 1-E_{i}}$, When $E_{i}$ is infinitely close to 1 , the molecule will become very small, so a small change in the entropy value will cause a double change in the weight, which is unreasonable. This article optimizes the traditional entropy weight method. The calculation formula is changed to $w_{i}=\frac{1-E_{i}+\bar{E}}{\sum_{i=1}^{k} 1-E_{i}+\bar{E}}$ $\bar{E}$ is the mean value of information entropy.

\subsection{AHP-improved entropy weight method- TOPSIS combined evaluation}

TOPSIS (Approximate to Ideal Point Sorting Method) is mainly used to make multi-objective decision-making on limited solutions. Based on the normalization of the original data, select the optimal solution and the worst solution, and calculate the relative optimal solution and the worst solution of each solution. The distance is used for sorting and comprehensive evaluation of each program. If there are $m$ schemes and $k$ evaluation indicators this time, the initial matrix $P, P_{i j}$ represents the $\mathrm{j}$-th index value of the i-th object, and the steps of using AHP-improved entropy method-TOPSIS combined evaluation are as follows:

(1) Construct the original matrix $P$, $P=\left(\begin{array}{ccc}p_{11} & \cdots & p_{1 k} \\ \vdots & \ddots & \vdots \\ p_{m 1} & \cdots & p_{m k}\end{array}\right)$

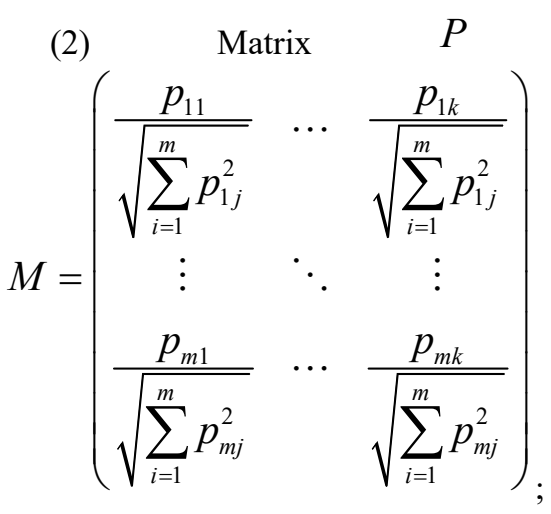

normalization,

(3) Use AHP-improved entropy method to obtain weight vector $w=\left[w_{1}, \cdots, w_{k}\right]$;

(4) Calculation index weighted evaluation matrix

$V=\left(\begin{array}{ccc}\frac{p_{11} * w_{1}}{\sqrt{\sum_{i=1}^{m} p_{1 j}^{2}}} & \ldots & \frac{p_{1 k} * w_{k}}{\sqrt{\sum_{i=1}^{m} p_{1 j}^{2}}} \\ \vdots & \ddots & \vdots \\ \frac{p_{m 1} * w_{1}}{\sqrt{\sum_{i=1}^{m} p_{m j}^{2}}} & \cdots & \frac{p_{m k} * w_{k}}{\sqrt{\sum_{i=1}^{m} p_{m j}^{2}}}\end{array}\right), v_{i j}=m_{i j} * w_{j} ;$

(5) Calculate positive ideal solution $V^{+}=\left[v_{1}^{+}, \cdots, v_{k}^{+}\right], \quad v_{j}^{+}=\max _{i \in\{1, \cdots, m\}} v_{i j}$; negative ideal solution $V^{-}=\left[v_{1}^{-}, \cdots, v_{k}^{-}\right], v_{j}^{-}=\min _{i \in\{1, \cdots, m\}} v_{i j}$;

(6) Calculate the Euclidean distance from each scheme to the positive and negative ideal solution, $S_{i}^{+}=\sqrt{\sum_{j=1}^{k}\left(v_{i j}-v_{j}^{+}\right)^{2}} \quad S_{i}^{-}=\sqrt{\sum_{j=1}^{k}\left(v_{i j}-v_{j}^{-}\right)^{2}}$

(7) Calculate the final evaluation value, and sort the best options according to the evaluation value, $g_{i}=\frac{S_{i}^{-}}{S_{i}^{+}+S_{i}^{-}}$

AHP-improved entropy method-TOPSIS evaluation algorithm process is shown in Figure 1. 


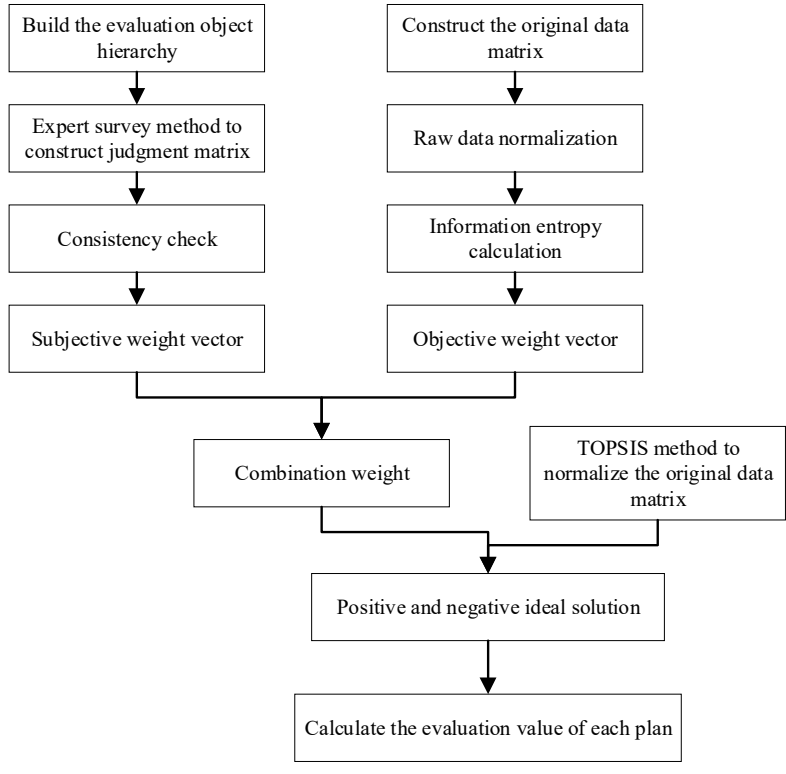

Figure 1 Flow chart of evaluation algorithm

\section{Conclusions}

On the basis of fully considering the characteristics of energy supply and demand in smart cities, integrate indicators reflecting economic benefits, social benefits, and environmental benefits into the links of energy efficiency, energy equipment, end users, etc., to build a multi-layered comprehensive benefits of smart energy systems The evaluation index system lays the foundation for the establishment of a comprehensive benefit evaluation model for smart energy systems. And a smart energy system evaluation method based on AHPimproved entropy method-TOPSIS is proposed, which can scientifically and reasonably evaluate the development of smart energy systems and provide systematic guidance for the construction and long-term development of smart energy systems. Based on the indepth study of the smart energy system, this paper constructs the indicator system of the smart energy system, uses the combination of AHP and entropy method to determine the weight of each indicator, and finally uses the TOPSIS method to calculate the closeness of the smart energy system to the positive and negative ideal solutions Therefore, comprehensive evaluation is performed. The design of this paper is unreasonable. When the subjective weight is determined by AHP, the opinions of multiple experts are not integrated. In the subsequent design, D-S theory can be used to fuse the judgment matrix of multiple experts to improve the credibility of the subjective weight.

\section{Acknowledgment}

The athors would like to thank the support of the project"Science and Technology Foundation of State Grid Corporation of China (SGHEJY00JJJS2000064)”.

\section{References}

1. Huo Lei, Niu Xiwu. Construction and Research on Performance Appraisal System of Vocational Education Group Based on Analytic Hierarchy Process[J]. Journal of Yangling Vocational and Technical College, 2019, 18(4): 46-49.

2. Yuan Peng, Zeng Yiqiao, Chen Zheng. Evaluation of Dynamic Factors of Urban Tourism Development Based on TOPSIS Method: A Case Study of Hunan Province[J]. Statistics and Decision, 2019(22): 5963.

3. Li Bing, Zhuang Wenhua, Sun Hailong. Application of Improved Entropy Method in Comprehensive Evaluation of Ecological Protection Effect of Rock Slope $[\mathrm{J}]$. China Soil and Water Conservation, 2019(9): 58-63.

4. Zhou Pengcheng, Cheng Yixin, Zeng Ming. Analysis of supply and demand characteristics and comprehensive benefit evaluation of multi-energy systems for smart cities[J].Shandong Electric Power Technology,2019,46(11).

5. Zhang Hairui. Research on the Comprehensive Evaluation Method of Smart Grid[D]. Shanghai: Shanghai Jiaotong University, 2012.

6. Lu Yuliang, Chen Zheng, Duan Qing, Ma Chunyan, Liu Chiyi, Zhang Guobao. Evaluation of smart energy system based on AHP-improved entropy method-TOPSIS[J]. Smart Grid, 2020, 10(1): 21-28. 